\title{
Hyponatraemia in a prepubertal middle-aged woman
}

\author{
A M Wägner, J Puig, M Rigla, S Ferrer, S Webb, A Pérez
}

A 71-year-old woman was referred to the hospital because of hyponatraemia. She had presented with nausea and vomiting one week before admission, and bradypsychia in the 24 hours prior to admission. The patient had never married. She reported primary amenorrhea and an absence of sexual development which had never been studied. She had a 10-year history of hypertension, atrial fibrillation, and back-ache, and a two-year history of hypercholesterolaemia. In the last year, she had experienced increased weakness and weight gain of $10 \mathrm{~kg}$. She was on a salt-free diet, amyloride and digoxin. Family history was irrelevant. Physical examination showed a well-hydrated, stuporous woman, weight $65 \mathrm{~kg}$, height $1.55 \mathrm{~m}$. Her blood pressure was 185/70 $\mathrm{mmHg}$, and pulse 92 beats/min. She had dorsal kyphosis, and there was no goitre or pterigium. She had no pubic or axillary hair, her breasts had developed to Tanner's stage II, and external genitalia were prepubertal. Her voice was hoarse, and eye funduscopy revealed hypertensive retinopathy.

Initial laboratory studies revealed plasma sodium of $111 \mathrm{mmol} / 1$ and potassium of $4.1 \mathrm{mmol} / \mathrm{l}$, and urinary sodium and potassium excretion of $47 \mathrm{mmol} / 1$ and $11 \mathrm{mmol} / 1$, respectively. Because of poor response to fluid therapy, cortisol before and 30 minutes after intravenous administration of $250 \mu \mathrm{g}$ soluble adrenocorticotropin (ACTH) was measured (table), and hydrocortisone was started. Laboratory results are displayed in the table. A chest X-ray showed several crushed vertebra, and bone densitometry (dual energy X-ray densitometry) revealed trabecular osteoporosis. An abdominopelvic ultrasound displayed a small uterus and atrophic anexi. Cerebral magnetic resonance imaging (MRI) revealed a normal-sized empty sella turcica (figure).

Table Main hormonal findings

\begin{tabular}{lcl}
\hline & Results & $\begin{array}{l}\text { Reference } \\
\text { interval }^{*}\end{array}$ \\
\hline $\begin{array}{l}\text { ACTH test: cortisol (nmol/l) } \\
\quad 0 \text { min }\end{array}$ & 77 & $195-780$ \\
$\quad 30$ min & 241 & $>500 \dagger$ \\
TSH (mIU/l) & 2 & $0.25-5$ \\
Free T4 (pmol/l) & 9 & $9.5-20$ \\
LH $(\mathrm{IU} / \mathrm{l})$ & $<0.6$ & $39.7-103.5$ \\
FSH $(\mathrm{IU} / \mathrm{l})$ & $<0.5$ & $34.4-96$ \\
Oestradiol (nmol/l) & $<0.11$ & $<0.36$ \\
Prolactin $(\mu \mathrm{g} / \mathrm{l})$ & 10.9 & $3.2-23$ \\
GH $(\mathrm{mIU} / \mathrm{l})$ & $<0.13$ & $0-10$ \\
IGF-1 $(\mu \mathrm{g} / \mathrm{l})$ & $<72$ & $142-389$ \\
\hline
\end{tabular}

Abbreviations: TSH, thyroid-stimulating hormone; T4, thyroxine; LH, luteinising hormone; FSH, follicle-stimulating hormone; GH, growth hormone; IGF, insulin-like growth factor. * Reference interval in our laboratory for menopausal women. †The increase after the injection of ACTH should be at least $220 \mathrm{nmol} / 1$.

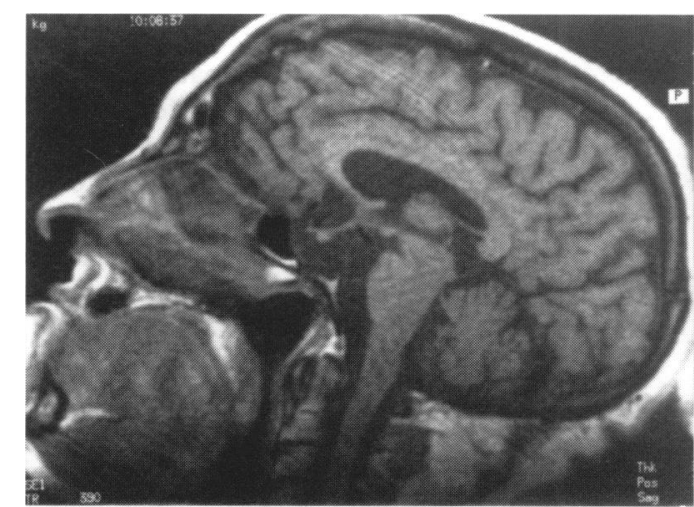

Figure Brain MRI
Endocrinology,

Hospital de Sant Pau, Antonio M Claret 167, 08025-Barcelona,

Spain

A $M$ Wägner

J Puig

$M$ Rigla

$S$ Ferrer

$S$ Webb

A Pérez

Accepted 16 December 1997

\section{Questions}

1 What is the diagnosis?

2 When did the patient's disorder begin?

3 What is the cause of hyponatraemia in this case? 
Answers

QUESTION

Panhypopituitarism due to an empty sella turcica. Laboratory results show disfunction of pituitary-adrenal, thyroidal, gonadal and somatotropic axes.

QUESTION 2

Our patient reported primary amenorrhea, showed a complete absence of pubertal development and was, on average, $20 \mathrm{~cm}$ shorter than the rest of her family. These data suggest that she was prepubertal when her disorders began. The clinical presentation of the remaining deficiencies is difficult to place in time. Nevertheless, she reported symptoms suggesting hypothyroidism and adrenal insufficiency in the last year.

QUESTION 3

Severe and sudden onset of hyponatraemia is an extremely unusual presentation of ACTH deficiency. Thus, in this case, a more likely explanation for severe hyponatraemia is a combination of factors, comprising ACTH deficiency, hypothyroidism, a salt-free diet and the use of diuretics, finally triggered by vomiting.

\section{Discussion}

The primary Empty Sella Syndrome (ESS) is more frequent in middle-aged, obese, multiparous women suffering from high blood pressure, and headaches are the most prevalent symptom. ${ }^{1}$ However, children with the ESS are neither obese nor hypertensive, nor do they report headaches. A higher prevalence among girls is not found, and the size of the sella turcica is usually normal. ${ }^{2}$ ESS is rare in paediatric patients, but endocrinological abnormalities are relatively common in this group, growth retardation and delay in sexual maturation being the most frequent. ${ }^{3}$

The normal size of the sella turcica and the absence of headaches in this patient agree with the previously described features of ESS presenting in childhood. Interestingly, she was obese and hypertensive, frequent findings in the adult with ESS, but highly prevalent in women in this age-group.

1 Christy NP, Warren MP. Other clinical syndromes of the hypothalamus and anterior pituitary. In: L J DeGroot, ed, DeGroot's Endocrinology, vol 1. Philadelphia: Saunders Company, 1989; pp 444-6.

2 Zucchini S, Ambrosetto P, Carla G, Tani G, Franzoni E Cacciari E. Primary empty sella: differences and similarities between children and adults. Acta Paediatr 1995;84:1382-5.

3 Shulman D, Martínez CR, Bercu BB, Root AW. Hypotalamic-pituitary dysfunction in primary empty sella syndrome in childhood. $\mathcal{F}$ Pediatr 1986;108:540-4.

\section{Learning points}

- empty sella syndrome is more frequent in obese and hypertensive middle-aged women

- endocrinological disorders are the most frequent form of presentation of the empty sella syndrome in children

- even if diagnosis is made in adulthood, clinical features and a normal-sized sella turcica point toward an initiation in childhood

The different presentation of ESS in adults and children or teenagers could be explained by differences in the aetiology and expression of associated clinical abnormalities. When an ESS is found in combination with an enlarged sella turcica, a common feature in adults, it has been hypothesized that it is the result of an acquired intrasellar disorder. ${ }^{4}$ The normal size of the sella turcica and the absence of non-endocrinological alterations in children, suggest that ESS in children may have a different aetiology, possibly a congenital midline abnormality, as in pituitary dwarfism. ${ }^{2}$ In addition, more restrictive criteria for the performance of MRI or computed tomography scan in children, and the lower expression of obesity and hypertension in children and teenagers may contribute to the different presentation of ESS in adults and children. ${ }^{2-5}$

\section{Patient outcome}

After treatment with hydrocortisone, serum sodium values normalised, and the patient improved, regaining full consciousness. Thereafter, levothyroxin and oestrogen-progestagens were started. A water deprivation test, after pituitary substitution with hydrocortisone and levothyroxin, followed by desmopressin administration, ruled out diabetes insipidus.

\section{Final diagnosis}

Panhypopituitarism due to empty sella turcica.

Keywords: sella turcica; empty sella syndrome; hypopituitarism; hyponatraemia

4 Bjerre P, Syldensted C, Riishede J, Lindblom J. The empty sella and pituitary adenomas. A theory on the causal sella and pituitary adenomas. A theory on
relationship. Acta Neurol Scand 1982;66:82-92.

5 Cacciari E, Zucchini S, Ambrosetto P, et al. Empty sella in children and adolescents with possible hypothalamic disorders. $\mathcal{F}$ Clin Endocrinol Metab 1994;78:767-71. 